The Orthodontic-Oral Surgery interface: Part One: A service evaluation and an overview of the diagnosis and management of common anomalies

Sharif $\mathrm{MO}^{1}$, Lyne $\mathrm{A}^{2}$, Parker $\mathrm{K}^{3}$, Chia MSY ${ }^{4}$

1. Mr Mohammad Owaise Sharif

Clinical Lecturer/Honorary Consultant in Orthodontics, MClinDent Deputy Programme Director, University College London Eastman Dental Institute

2. Miss Alexandra Lyne

Specialty Registrar in Paediatric Dentistry, Guy's and St Thomas's Hospitals NHS Foundation Trust

3. Miss Kate Parker

Post-CCST in Orthodontics, Eastman Dental Hospital and Croydon University Hospital

4. Mr Matthew SY Chia,

Consultant Orthodontist, Croydon University Hospital 


\title{
The Orthodontic-Oral Surgery interface. Part One: A service evaluation and overview of the diagnosis and management of common anomalies.
}

\begin{abstract}
The Orthodontic-Oral Surgery interface is important for patients requiring multidisciplinary management of complex dental anomalies. This two part series details a service evaluation of a busy district general hospital joint dento-alveolar clinic, the demographics of the patients attending and their presentations. Part One details the management of soft tissue anomalies, cysts and supernumerary teeth and Part Two details the management of anomalies in eruption, transpositions and infraoccluded primary molars. Both part one and two emphasis the role of the General Dental Practitioner in the management of these complex anomalies.
\end{abstract}

\section{$\underline{\text { Service Evaluation }}$}

\section{Introduction}

The Joint Dento-Alveolar (JDA) clinic at Croydon University Hospital (CUH) has been established for more than 15 years. This was in response to the complex nature of referrals received at CUH. This multidisciplinary clinic supports specialists and hospital based consultants in the management of complex dental anomalies. The team comprises of senior members from the hospital Orthodontic and Oral Surgery departments as well as hospital based Dental Foundation and Specialty Trainees. The availability of this clinic allows for input from both the Orthodontic and Oral Surgery specialties at one visit allowing for a holistic, comprehensive treatment plan to be developed. This process ensures that all of the available treatment options can be discussed, and enables patients to be fully involved in their decision making, and therefore able to provide informed consent for their treatment. In addition, a service evaluation conducted in 2013 revealed that this clinic enhanced the patient experience. $^{1}$

The aim of this two part series is to outline the origin of referrals to the JDA clinic and the presenting anomalies. Furthermore, a summary of the most common and 
interesting conditions as well as their management will be provided. Part One will cover soft tissue anomalies, dentigerous cysts, transpositions and supernumerary teeth. Part Two will focus on impacted teeth (incisors, canines, second premolars and molars), as well as generalised delayed eruption, primary failure of eruption, ankylosed incisors and infra-occluded deciduous molars. Both part one and part two of the series detail the important role of the General Dental Practitioner (GDP) in identifying and diagnosing these complex anomalies as well as the importance of onward referral to secondary care for specialist opinions and management where required.

\section{Method}

A prospective analysis of patient hospital notes was performed for 100 consecutive new patients attending the JDA at CUH from November 2014 to September 2015. Data was collected using a pre-designed and piloted data collection sheet. The following data was collected for each patient:

- Age

- Gender

- Diagnosis / reason for referral

- The patient's pathway from referral to attendance at the JDA clinic

Data was entered into a Microsoft Excel spreadsheet and summary statistics were produced and evaluated.

\section{Results}

To attend the JDA clinic patients are initially referred internally from different departments within CUH. Table 1 outlines the origin of both the original referral to the hospital, and the source of the internal referral to the JDA.

The majority of patients were originally referred to CUH by a specialist Orthodontist in practice (79\%), followed by General Dental Practitioners (GDP) (20\%), and only $1 \%$ were referred by a district general hospital. Internally, the majority of patients on the JDA were referred from the CUH Orthodontic department (92\%), with a much smaller number referred from the CUH Oral Surgery department (8\%). 


\begin{tabular}{|l|c|}
\hline Origin of new patient referrals to CUH & $\%$ \\
\hline Orthodontic Specialist & 79 \\
\hline General Dental Practitioners & 20 \\
\hline District General Hospital & 1 \\
\hline \multicolumn{2}{|c|}{} \\
\hline Origin of internal patient referrals to the JDA clinic & $\%$ \\
\hline Orthodontic Department & 92 \\
\hline Oral Surgery Department & 8 \\
\hline
\end{tabular}

Table 1. Origin of new referrals to CUH and internal referral to the JDA clinic.

Figure 1 illustrates the profile of anomalies presenting on the JDA clinic for the 100 patients included in the service evaluation. Ectopic canines were the most frequently occurring anomaly accounting for $49 \%$ of the referrals. Supernumerary teeth accounted for $16 \%$ of referrals and impacted premolars 10\%. All other anomalies accounted for only a small percentage of the referrals. Four percent of patients had grossly carious first premolars and were seen on the clinic for confirmation of an extraction pattern.

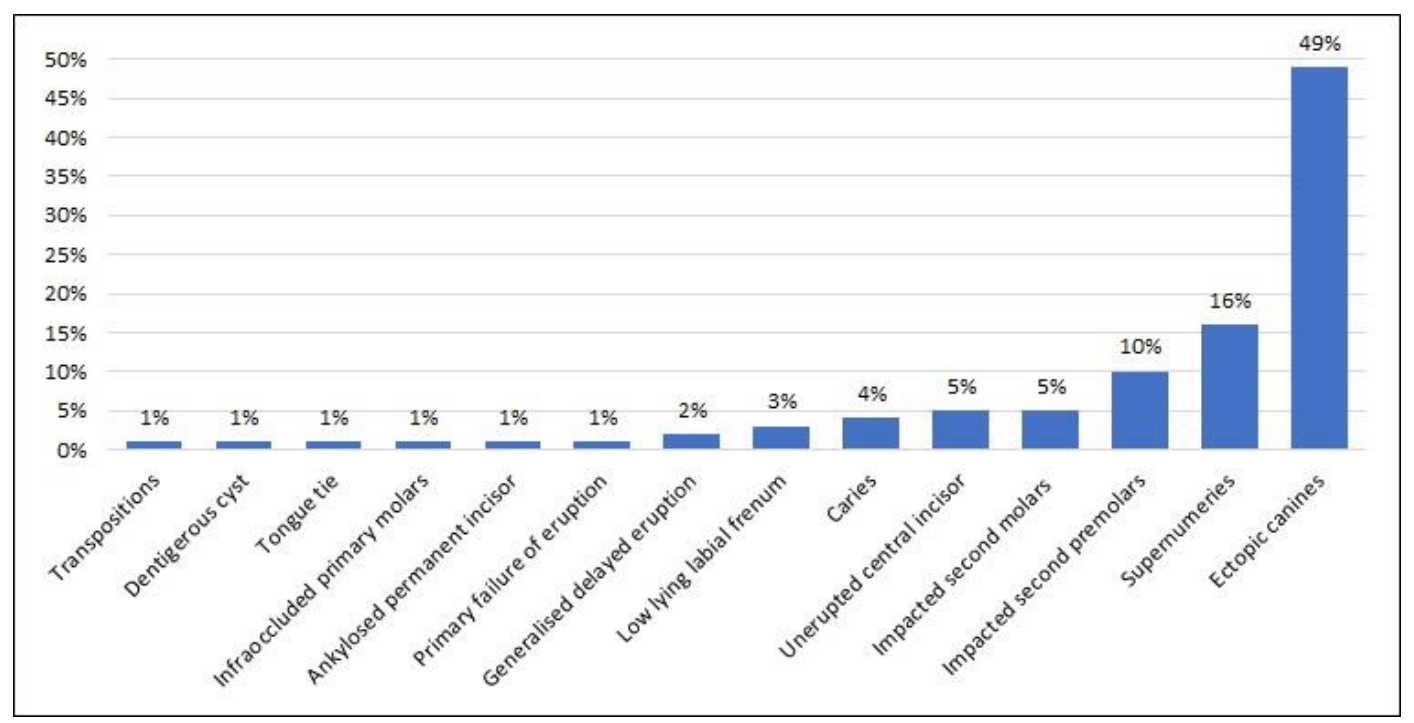

Figure 1. The profile of anomalies seen as new referrals on the JDA clinic.

Table 2 shows the patient demographic details relating to each anomaly seen on the JDA clinic. The majority of patients were female (54\%), the mean age was 17 years, with a range of $8-50$ years. 


\begin{tabular}{|l|c|c|c|}
\hline \multicolumn{1}{|c|}{ Presenting Anomaly } & Male:Female & $\begin{array}{c}\text { Average Age } \\
\text { (Years) }\end{array}$ & $\begin{array}{c}\text { Age range } \\
\text { (Years) }\end{array}$ \\
\hline Ectopic Canines & $17: 32$ & 17 & 11 to 50 \\
Supernumeries & $14: 2$ & 13 & 9 to 18 \\
Impacted second premolars & $3: 7$ & 15 & 12 to 28 \\
Impacted second molars & $3: 2$ & 15 & 13 to 18 \\
Unerupted central incisors & $4: 1$ & 10 & 8 to 14 \\
Caries & $2: 2$ & 11 & 8 to 14 \\
Low lying labial frenum & $1: 2$ & 14 & 11 to 16 \\
Generalised delayed eruption & $0: 2$ & 14 & 13 to 15 \\
Primary failure of eruption & $1: 0$ & 8 & N/A \\
Ankylosed permanent incisor & $0: 1$ & 15 & N/A \\
Infraoccluded primary molars & $1: 0$ & 16 & N/A \\
Tongue tie & $0: 1$ & 12 & N/A \\
Dentigerous Cyst & $0: 1$ & 14 & N/A \\
Transpositions & $0: 1$ & 13 & N/A \\
\hline Total & $\mathbf{4 6 : 5 4}$ & $\mathbf{1 5}$ & $\mathbf{8}$ to 50 \\
\hline
\end{tabular}

Table 2. Demographic details of the anomalies seen on the JDA clinic.

\section{Discussion}

The majority of new patients attending the JDA clinic were originally referred by specialist Orthodontists (79\%). This supports the view that the throughput of this clinic comprises a variety of complex cases and that this clinic is invaluable in supporting primary care Orthodontic services in Croydon.

Ectopic canines (49\%) were the most common presenting anomaly, followed by supernumerary teeth $(16 \%)$. The majority of patients with ectopic canines were female and those with supernumeraries were male, which supports previous reports in the literature. ${ }^{2,3}$

Completion of this service evaluation of the JDA clinics has allowed the department to recognise the high demand for such multidisciplinary clinics due to the high number of patients presenting with abnormalities which required multidisciplinary assessment and management. Following the service evaluation, more Oral Surgery specialists were allocated for the JDA clinics and the clinics were run more frequently. The service evaluation also aided the evolution of the JDA clinics by recognising the need for the use of enhanced imaging modalities such as Cone Beam 
CT scans (CBCT) and the development of patient pathways for the multidisciplinary management of many of these complex patients.

Given the breadth of dento-alveolar pathologies (both common and rare) presenting to this clinic, we feel that it is important for the GDP to have an understanding of these conditions, and what types of management may be discussed when these patients are referred. This article will provide the reader with an overview of the aetiology, prevalence, classification, diagnosis, features and management of soft tissue anomalies, cysts, and supernumerary teeth. Part Two in this series focuses on impacted teeth as well as generalised delayed eruption, primary failure of eruption, ankylosed incisors and infra-occluded deciduous molars.

\section{Common Anomalies}

\section{Low Lying Labial Frenum}

Definition: The low insertion of the upper or lower labial frenum into the gingival tissue that can causes aesthetic or functional problems (Figure 2). ${ }^{4}$

Aetiology: Variation of normal anatomy, with a possible genetic link.

Prevalence: $26.1 \%{ }^{4}$

Classification: Frenums can be classified according to the tissue into which the frenal fibres attach; mucosal (at the mucogingival junction), gingival (within attached gingiva), papillary (into the interdental papilla) or papilla penetrating (into the palatine papilla).

Diagnosis: A low lying labial frenum can usually be seen on clinical examination. If there is blanching of the interdental papilla in the midline when the upper lip is everted, the frenum may be contributing to a midline diastema. However, commonly it may not be possible to ascertain whether a low lying labial frenum is causing a midline diastema or if it is a consequence of a midline diastema. In either case the management of the low lying labial frenum will be the same.

Features: A midline diastema is often associated with a low lying labial frenum. They may also be related to existing dento-alveolar anatomy including spaced teeth and unerupted teeth. Low frenums can cause gingival recession and can easily be traumatised, for example, when toothbrushing. 
Management: Low labial frenums may occasionally resolve spontaneously. Even if they do not resolve spontaneously the majority of low lying frenums will not require treatment. Interventional management (frenectomy) may be indicated if the low frenal attachment is associated with a midline diastema, if there is gingival recession or if there is difficulty maintaining oral hygiene around the frenum.

If a low lying frenum is associated with a midline diastema and is assessed as being likely to prevent orthodontic closure of the diastema a frenectomy is indicated. The frenectomy can be carried out prior to orthodontic treatment, during treatment, or following removal of the orthodontic appliances. A frenectomy during orthodontic treatment carried out just prior to space closure allows good surgical and space closure can be started following the frenectomy and contraction of the scar tissue will aid closure of the diastema. A frenectomy prior to orthodontic treatment allows for better surgical access, however, scar tissue may have formed once the patient is ready to commence orthodontic space closure and this scar tissue may impede space closure. Frenectomies can also be carried out following orthodontic treatment. In this instance, surgical access may be difficult but there is the advantage that scar tissue contraction may contribute to keeping the diastema space closed. Despite the proposed advantages and disadvantages of the different timing of carrying out a frenectomy there is little evidence to support the type and timing of any surgical intervention. $^{5}$

Role of the GDP: To diagnose the presence of low lying frenums and give appropriate oral hygiene advice to prevent recession and gingival trauma. Referral onward to secondary care if the frenum is causing aesthetic or functional concerns. 


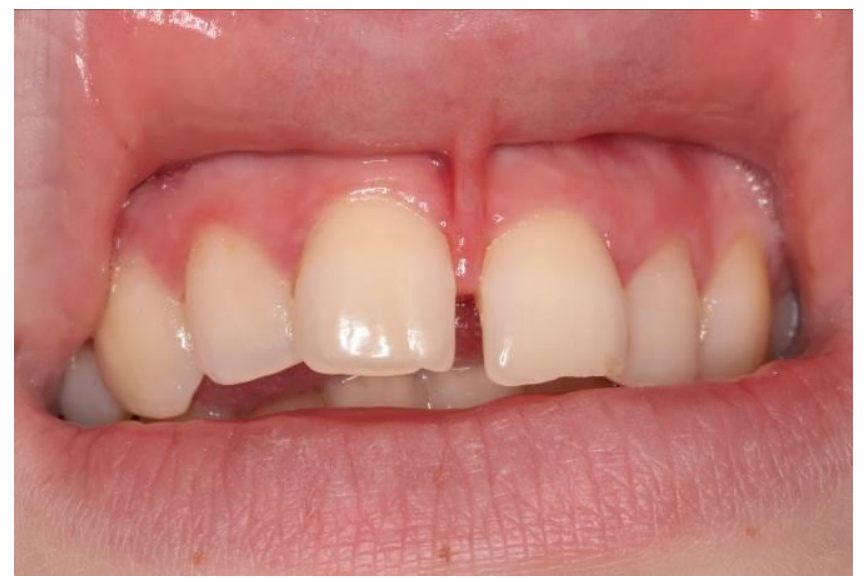

Figure 2. A low lying labial frenum.

\section{Tongue-Tie}

Definition: Often referred to as anklyoglossia, a tongue-tie usually refers to a lingual frenum that causes anatomical restriction of tongue movement (Figure 3).

Aetiology: Variation of normal anatomy.

Prevalence: $4.2 \%$ in newborns. ${ }^{6}$

Classification: There is no uniform classification of tongue-ties, however they are commonly classified according to whether they are anterior or posterior (or submucosal). Anterior (visible) tongue ties may insert to the tip of the tongue or ventral surface.

Diagnosis: Based on a history of functional difficulties with tongue movement, supported by clinical examination. The mid tongue may not elevate compared to the lateral aspects.

Features: In the newborn, breastfeeding problems (nipple pain or difficulty latching) may be present. Theoretically, certain consonant sounds ('s', 'th', 'r') could be affected by impeded tongue movement, however, there is a lack of clinical evidence for this.

Management: Tongue ties may resolve spontaneously over time. Frenotomy, frenectomy, or frenuloplasty can be performed to release the tongue-tie. However, there is little evidence available regarding which surgical method may be superior. ${ }^{7}$ Surgery may be indicated if the infant is having feeding difficulties, however, there is little evidence on whether surgical treatment or leaving and monitoring the tongue-tie is preferable. ${ }^{7}$ The timing of surgery for tongue ties can be classified 'early' or 'late'. Early surgery is carried out in early infancy and has the advantage that no analgesia or 
anaesthesia is usually required due to the tongue having limited nerve endings at this time. Late surgery often requires a local or general anaesthetic, however, there is limited evidence on whether early or late surgery is superior.

Role of the GDP: The GDP can diagnose tongue ties and reassure parents of the diagnosis. If there are feeding concerns with infants an onward referral is indicated.

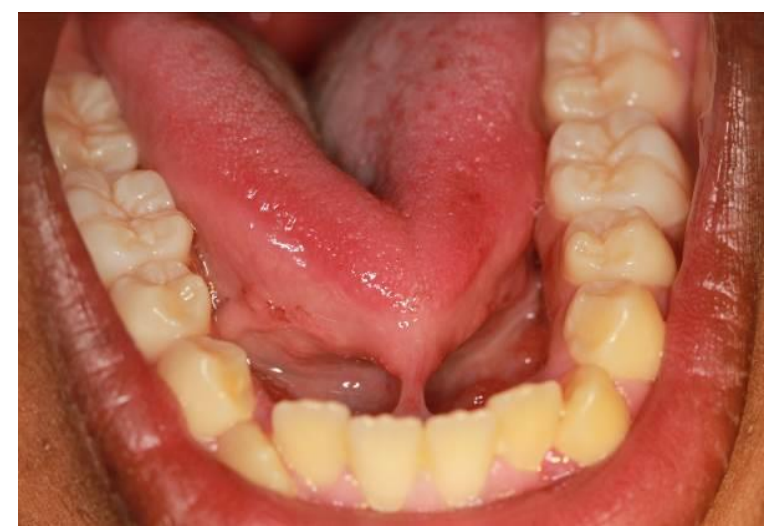

Figure 3. A tongue-tie.

\section{Dentigerous Cyst}

Definition: A cyst is an abnormal, lined, fluid filled cavity within the body. A dentigerous cyst is a developmental cyst that is associated with the crown of an unerupted or partially erupted tooth (Figure 4).

Aetiology: Proliferation of enamel epithelium after enamel formation. The pathogenesis is poorly understood; one theory is that proliferation is induced by the osmotic pressure during an extended period of impaction.

Prevalence: $1.2 \%{ }^{8}$

Classification: According to the teeth associated with the cyst.

Diagnosis: A provisional diagnosis is made from clinical and radiographic findings of an unerupted tooth with an associated radiolucency enveloping the tooth. Cone beam CT (CBCT) imaging may help determine the size and anatomical structures associated with a cyst. A definitive diagnosis is made through histological examination of the lining of the cyst. ${ }^{9}$

Features: Unerupted or impacted teeth, displaced or mobile adjacent teeth, bony destruction, root resorption of adjacent teeth, crowding, spacing.

Management: Depending on the size and location, cysts may be managed by either enucleation or marsuplisation (decompression) followed by enucleation after the 
lesion shrinks. Diagnosis is confirmed from histological analysis of the lining. The involved tooth may be allowed to spontaneously erupt (if root formation is incomplete), orthodontically aligned, or extracted. ${ }^{10}$ The dentigerous cyst presenting in Figure 4 was managed by enucleation.

Role of the GDP: The GDP may be the first clinician to suspect a dentigerous cyst following a clinical and radiographic examination. If a cyst is suspected the patient should be referred to secondary care for a further assessment and for management of the cyst.

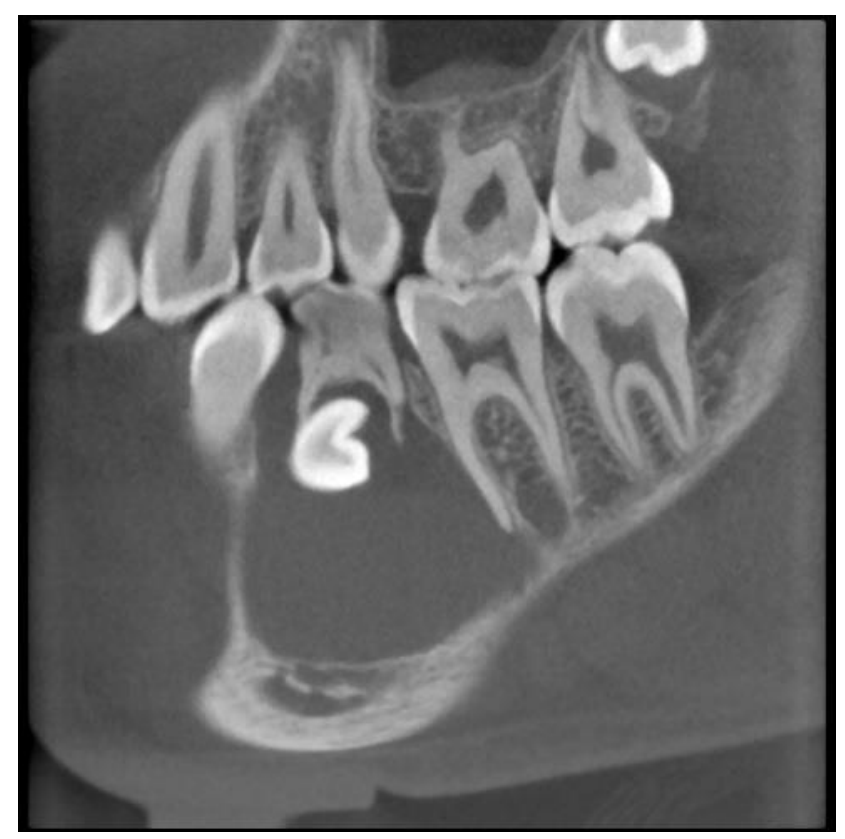

Figure 4. A sagittal section of a CBCT image showing a dentigerous cyst associated with the lower right second premolar.

\section{Supernumerary Teeth}

Definition: A supernumerary tooth is a tooth occurring in addition to the normal series of teeth (Figure 5).

Aetiology: There are multiple aetiological theories including; hyperactivity of the dental lamina, genetic factors, and the now largely discounted theories of dichotomy of the tooth bud and atavism. Supernumeraries can be associated with cleft lip and palate and with certain syndromes, for example: cleidocranial dysostosis and Gardener's syndrome.

Prevalence: $0.91-2.1 \% .^{3}$ 
Classification: According to morphology or location (Table 3).

Diagnosis: Erupted supernumeraries can be detected by conducting a dental examination. Unerupted supernumeraries are most commonly detected as an incidental find on radiographs. If plane film radiographs are unclear a CBCT scan may be required to confirm the presence, morphology and location of some supernumerary teeth. Supernumerary teeth may also be unclear or undetected on Dental Panoramic Tomograph (DPT) radiographs if they are outside of the focal trough. In these situations, further imaging, either with intra-oral plain films or CBCTs may be indicated. It is important to appreciate that supernumeraries can develop later in life. ${ }^{11}$ Therefore, the absence of any supernumeraries in the early years does not rule out their development in the later years.

Features: Complications of the adjacent permanent teeth, such as dilaceration, failed or delayed eruption, impaction, rotation, root resorption, crowding, spacing, and retained primary teeth. The supernumerary itself may undergo cystic change, or rarely, migration into the nasal cavity or maxillary sinus. ${ }^{12}$

Management: If there is no associated pathology or underlying malocclusion, these supernumeraries may be left in situ. If unerupted, periodic radiographic review is recommended to assess for any cystic change or damage to adjacent structures. Alternatively, supernumeraries may require extraction, if there is any associated pathology or if orthodontic treatment is required and if the supernumerary would interfere with tooth movement. Unerupted supernumeraries can be extracted surgically or occasionally supernumerary teeth erupt and then a simple extraction can be undertaken.

Role of the GDP: The GDP can identify and diagnose supernumerary teeth and they can also often identify if there is any associated pathology. Referral to secondary care for a specialist opinion is advisable. If supernumerary teeth are left in situ, the GDP can carry out regular reviews with radiographic monitoring and re-refer if required. If the supernumerary is to be extracted, simple extractions of erupted supernumeraries may be undertaken by the GDP. However, surgical extraction of unerupted supernumeraries is often undertaken in secondary care by a specialist Oral Surgeon. 


\begin{tabular}{|c|c|c|}
\hline \multirow{4}{*}{$\begin{array}{l}\frac{1}{00} \\
\frac{0}{0} \\
\frac{0}{2} \\
\frac{0}{2} \\
\frac{0}{2}\end{array}$} & $\begin{array}{l}\text { Conical } \\
(\text { most } \\
\text { common) }\end{array}$ & $\begin{array}{l}\text { Small, peg-shaped tooth. Termed a mesiodens if it occurs } \\
\text { between the central incisors. This is the most common } \\
\text { presentation, with root formation equal to or ahead of the } \\
\text { permanent incisors. }\end{array}$ \\
\hline & Tuberculate & $\begin{array}{l}\text { Tooth with multiple cusps or tubercles, described as 'barrel- } \\
\text { shaped.' Commonly paired and located palatal to the maxillary } \\
\text { central incisors, with incomplete root formation. Can prevent } \\
\text { the incisors from erupting. }\end{array}$ \\
\hline & Supplemental & $\begin{array}{l}\text { Anatomical duplication of a normal tooth, found at the end of a } \\
\text { tooth series. Most commonly, distal to the maxillary lateral } \\
\text { incisor. }\end{array}$ \\
\hline & Odontome & $\begin{array}{l}\text { Benign, disordered growth of mature dental tissues, described } \\
\text { as compound (separate, small tooth-like structures) or complex } \\
\text { (single, irregular mass of dental tissue). }\end{array}$ \\
\hline \multirow{4}{*}{ : } & Mesiodens & $\begin{array}{l}\text { Most often a conical tooth located between and palatal to the } \\
\text { maxillary central incisors. }\end{array}$ \\
\hline & Parapremolar & $\begin{array}{l}\text { A supernumerary that forms in the premolar region and } \\
\text { resembles a premolar. }\end{array}$ \\
\hline & Paramolar & $\begin{array}{l}\text { A supernumerary molar, adjacent to a normal molar, situated } \\
\text { buccal, lingual/ palatal, or in the interproximal space. }\end{array}$ \\
\hline & Distomolar & A supernumerary tooth located distal to the third molars. \\
\hline
\end{tabular}

Table 3. Classification of supernumerary teeth according to morphology and location.

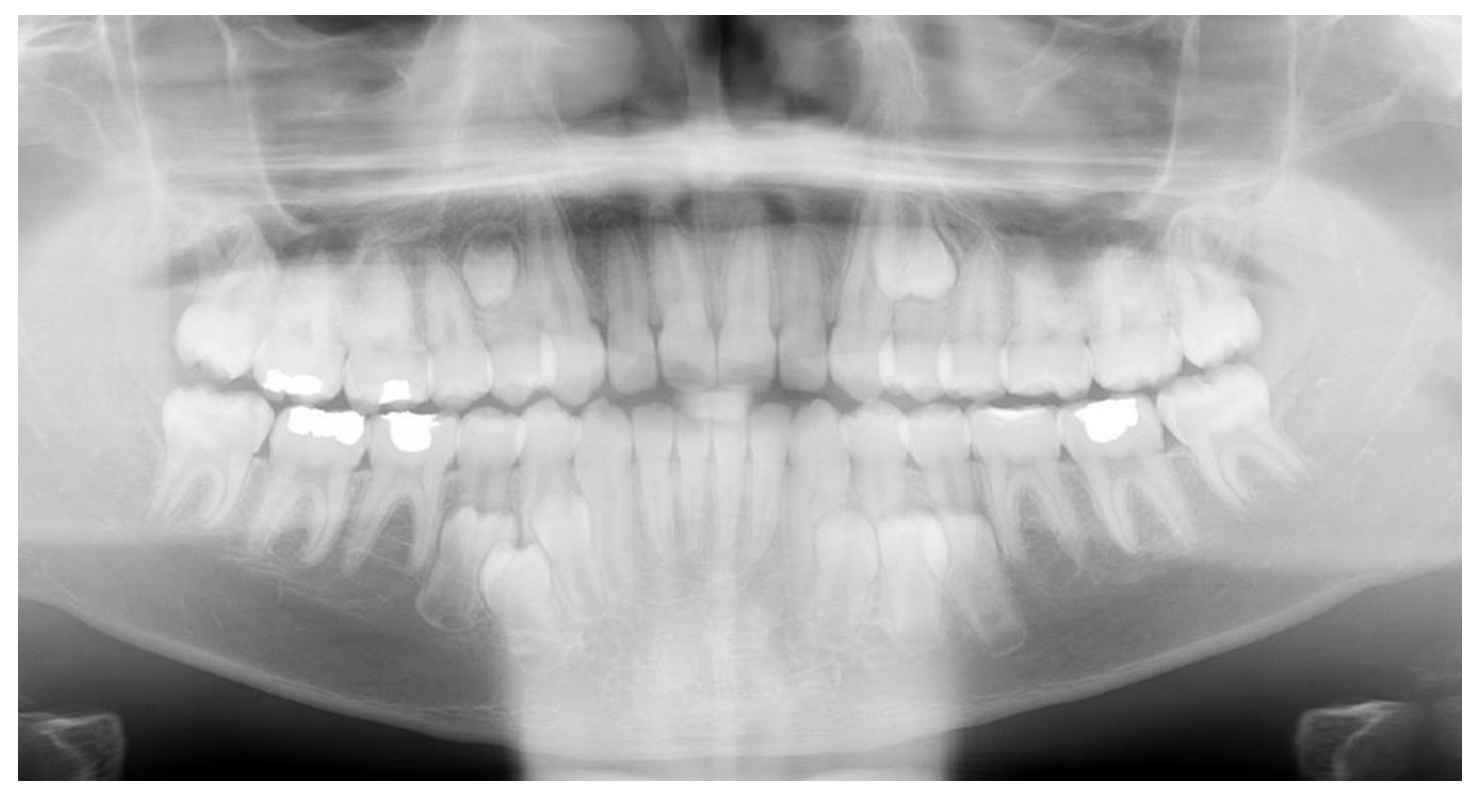

Figure 5. A DPT showing the presence of supplemental premolars in all quadrants. 


\section{Conclusion}

This article has summarised the profile of the cases seen on the JDA at CUH and given an overview of the common soft tissue anomalies, dentigerous cysts, and supernumerary teeth including their diagnosis, management and the role of the GDP. It has also highlighted the invaluable role of the GDP in identifying and aiding the diagnosis of these anomalies so that patients can be referred for specialist opinion in a timely manner. Part Two of this series focuses on anomalies in eruption, as well as transpositions and infra-occluded deciduous molars.

\section{Declaration of Interest}

The authors do not have any conflicts of interest. 


\section{References}

1. Khamashta-Ledezma L, Kordi Z, Radecki J, Davenport-Jones L, Chia M. Patient satisfaction with Croydon MDT dento-alveolar clinics. British Orthodontic Society Clinical Effectiveness Bulletin 2014; 8-10.

2. Mossey P A, Campbell H M, Luffingham J K. The palatal canine and the adjacent lateral incisor; a study of a west of Scotland population. BJO 1994; 21:169 -174.

3. Shah A, Gill D S, Tredwin C, Naini F B. Diagnosis and Management of Supernumery Teeth. Dent Update 2008; 35:510-520.

4. Boutsi E A, and Tatakis D N. Maxillary labial frenum attachment in children. Int J Paediatr Dent 2011; 21:284-8.

5. Devishree S K G, Shubhashini P V. Frenectomy: a review with the reports of surgical techniques. J Clinc Diagn Res 2012; 6:1587-92.

6. Ricke L A, Baker N J, Madlon-Kay D J, DeFor T A. Newborn tongue-tie: prevalence and effect on breast-feeding. J Am Board Fam Med 2005; 18:1-7.

7. Suter V G, Bornstein M M. Ankyloglossia: facts and myths in diagnosis and treatment. J Periodontol 2009; 80:1204-19.

8. Tortorici S, Amodio E, Massenti M F, Buzzuano F, Vitale F. Prevalence and distribution of odontogenic cysts in Sicily: 1986-2005. J Oral Sci 2008; 50:15-18.

9. Scholl R J, Kellett H M, Neumann D P, Lurie A G. Cysts and cystic lesions of the mandible: clinical and radiologic-histopathologic review. Radiographics 1999; 19:1107-24.

10. Motamedi M H, Talesh K T. Management of extensive dentigerous cysts. Br Dent J 2005; 198:203-206. 
11. Shah A, Gill D S, Tredwin C, Nani F B. Diagnosis and management of supernumerary teeth. Dental Update 2008; 35:510-520.

12. Garvey M T, Barry H J, Blake M. An overview of classification, diagnosis and management. J Can Dent Assoc 1999; 65:612-6. 